\title{
OBTAINING A PERMIT-TO-FLY FOR A HALE-UAV IN BELGIUM
}

\author{
J. Everaerts, N. Lewyckyj \\ Remote Sensing Unit, VITO, Boeretang 200, 2400 Mol - (jurgen.everaerts, nicolas.lewyckyj)@vito.be
}

Inter-Commission Working Group I/V

KEY WORDS: UAVs, Photogrammetry, Regulations

\begin{abstract}
:
Ever since 2000, VITO has been working on the Pegasus project. This involves a solar High Altitude Long Endurance Unmanned Aerial Vehicle (HALE-UAV) as a stratospheric platform for Earth Observation. This aircraft, called Mercator, is designed to fly for prolonged duration at altitudes up to $20 \mathrm{~km}$. The technology has been proven by the aircraft's manufacturer, QinetiQ (UK) by a series of test flights over the past years, culminating in a world record flight in duration of over 14 days duration. All test flights, however, were conducted in test ranges, where other air traffic does not pose a concern.

Pegasus aims to demonstrate the viability of stratospheric Earth Observation in Belgium, as a proof of concept for other areas around the world. The Belgian air space is completely different from a test range. More than 1 million aircraft movements take place over Belgium and Luxembourg every year, with routes to Amsterdam, Paris, Frankfurt, and London. Although Pegasus will usually be flying above this dense traffic, it does interfere with it during ascent and landing, and needs to be monitored during the cruise phase for safety reasons. Air traffic management in Belgium is a shared responsibility of Air Navigation Service Providers (ANSPs) Belgocontrol (civil), ATCC (military) and Eurocontrol MUAC (high altitude).

In 2010, VITO applied for a permit-to-fly for a test flight of one day duration. Although the Belgian Civil Aviation Authority (CAA) had issued a regulation on UAVs in 2007, it was the first application for a permit to fly in controlled airspace. The Belgian CAA decided to use it as a test for the procedures as well. A prerequisite for flying in controlled airspace was that the aircraft has to carry a mode-S transponder and navigation lights.

During first half of 2010, the ANSPs collaborated on a Temporary Operations Instruction and studied the safety impact of this flight on their operations. As an outcome, they decided that the Pegasus aircraft would be separated from other air traffic by a "moving box” around it. By the end of August, a permit-to-fly was issued by Belgian CAA.

The paper describes the application process, and highlights the issues that were raised by the ANSPs and Belgian CAA. This should be comparable to what authorities in other crowded places would impose, and hence be a good starting point for everyone trying to use UAVs for Earth Observation at altitudes above a few hundreds meters in most of the world.
\end{abstract}

\section{INTRODUCTION}

The Pegasus project was initiated at VITO, the Flemish Institute for Technological Research, in 2000, when it had been demonstrated that aircraft are able at high altitude $(15-20 \mathrm{~km})$ powered by solar energy by Aerovironment in the USA. At that altitude, above possible jet streams and the large majority of air traffic, there is an ambient wind speed minimum, so that even slowly moving aircraft can usually move around freely.

Pegasus' aim for the aircraft, called Mercator, was not just to climb to this altitude, but to stay there for long duration (i.e. weeks), serving as a platform for persistent remote sensing. Both aspects combined led to a requirement for an unmanned aircraft, powered by solar energy.

Another part of the project was to develop a camera that would be carried by the aircraft. This camera is called MEDUSA (Delauré, 2008), and it is undergoing final tests before acceptance in the Autumn of 2011.

Finally, an unmanned aircraft needs to be controlled from the ground and its telemetry and payload data need to be collected and processed. So, a Ground Control Station and a Central Data Processing Centre were set up, to automatically process the raw image data with GPS and IMU data (Biesemans, 2007).

Combining all these pieces, Pegasus is thus a complete remote sensing solution, from data-acquisition to delivery of products to the user.

In parallel to the technological development, we also set out to obtain the necessary permits to conduct flights in Belgium. This process was largely unknown to us at the beginning, and we soon found out that it simply did not exist. In the following sections, we will explain how we managed to obtain the permits. This is a case study and it applies to Belgium only.

\section{THE BELGIAN AIRSPACE}

\subsection{Situation}

Belgium is a small (approximately $30000 \mathrm{~km}^{2}$ ) country in Europe, surrounded by France, The Netherlands, Germany, Luxembourg and the North Sea, between 49 $30^{\prime}$ and $51^{\circ} 30^{\prime}$ North latitude. Brussels, its capital is also the host of several international institutions, such as the European Commission and NATO.

Due to the influence of the Atlantic Ocean, the climate is temperate, with significant rainfall around the year and average temperatures between $3^{\circ} \mathrm{C}$ and $18^{\circ} \mathrm{C}$. Cloud cover is significant but usually quite dynamic.

In terms of air traffic, Brussels airport offers connections to most of the European capitals next to intercontinental destinations in North America, Africa and Asia. Due to its geographical position, many flights originating from important international airports (in or close to London, Frankfurt, Paris, and Amsterdam) pass over the country. This results in a total of over 1 million overflights per year (Eurocontrol, 2010). 


\begin{tabular}{|l|l|l|l|}
\hline Class & Flight Rules & Aircraft Requirements & Minimum Services by ATC Unit \\
\hline A & IFR only & $\begin{array}{l}\text { ATC clearance before entry. } \\
\text { Comply with ATC instructions. }\end{array}$ & Separate all aircraft from each other. \\
\hline B & IFR and VFR & $\begin{array}{l}\text { ATC clearance before entry. } \\
\text { Comply with ATC instructions. }\end{array}$ & Separate all aircraft from each other. \\
\hline C & IFR and VFR & $\begin{array}{l}\text { ATC clearance before entry. } \\
\text { Comply with ATC instructions }\end{array}$ & $\begin{array}{l}\text { (a) Separate IFR flights from other IFR and VFR flights; } \\
\text { (b) Separate VFR flights from IFR flights; } \\
\text { (c) Pass traffic information to VFR flights on other VFR flights } \\
\text { and give traffic avoidance advice if requested. }\end{array}$ \\
\hline D & IFR and VFR & $\begin{array}{l}\text { ATC clearance before entry. } \\
\text { Comply with ATC instructions. }\end{array}$ & $\begin{array}{l}\text { (a) Separate IFR flights from other IFR flights; } \\
\text { (b) Pass traffic information to IFR flights on VFR flights and } \\
\text { give traffic avoidance advice if requested; } \\
\text { (c) Pass traffic information to VFR flights on IFR flights and } \\
\text { other VFR flights. }\end{array}$ \\
\hline E & IFR and VFR & $\begin{array}{l}\text { IFR flights to obtain ATC clearance } \\
\text { before entry and comply with ATC } \\
\text { instructions. } \\
\text { VFR flights do not require clearance. }\end{array}$ & $\begin{array}{l}\text { (a) Separate IFR flights from other IFR flights; } \\
\text { (b) Pass traffic information, as far as practicable, to IFR flights } \\
\text { on VFR flights; } \\
\text { (c) VFR flights in contact are to be given traffic information as } \\
\text { far as practicable. }\end{array}$ \\
\hline F & IFR and VFR & $\begin{array}{l}\text { Participating IFR flights are expected to } \\
\text { comply with ATC instructions. }\end{array}$ & $\begin{array}{l}\text { Separation provided, as far as possible, between aircraft that } \\
\text { have flight planned to operate IFR on ADRs. }\end{array}$ \\
\hline G & IFR and VFR & None & None \\
\hline
\end{tabular}

Table 1. Airspace Classification (CAP493, 2011)

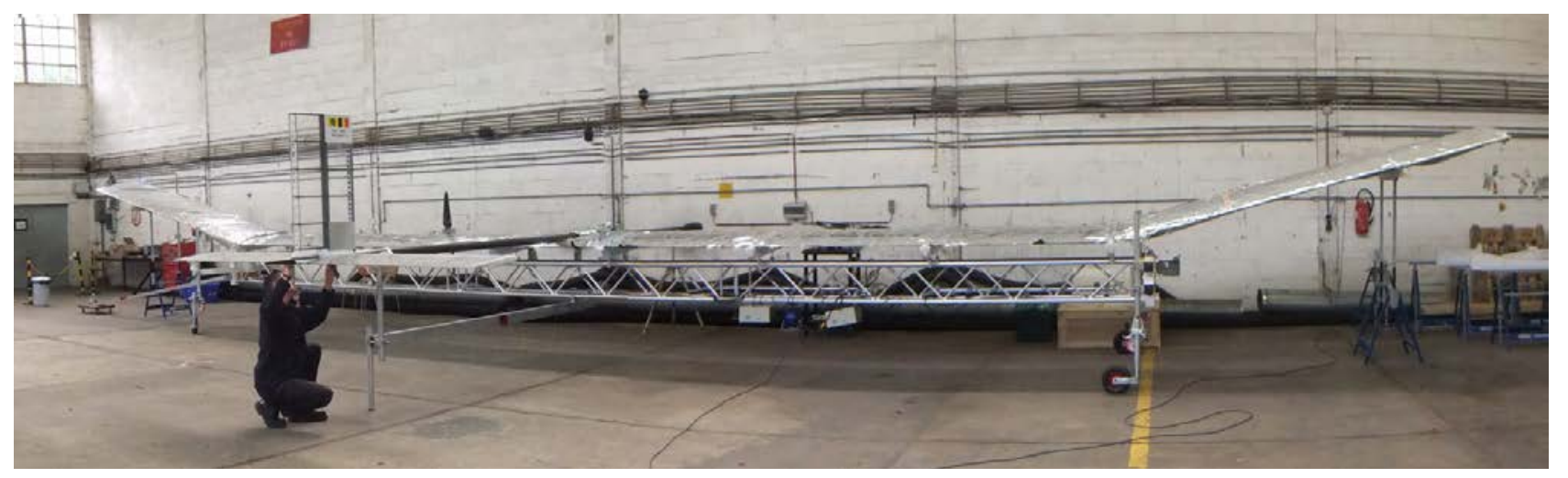

Figure 1. Mercator being prepared at Bertrix airfield

\subsection{Airspace structure}

The airspace above Belgium is classified using the international classes A-G, that depend on (a) the flight rules, (b) requirements on the aircraft and (c) the minimal services provided by Air Traffic Control. This is summarized in Table 1. In Belgium, however, only class $\mathrm{C}$ and $\mathrm{G}$ are used. As one may expect in view of the density of the air traffic and the modest size of the country, class $G$ airspace is limited to low altitude, and away from airports and cities. This class is used by many small UAV users in the photogrammetry and remote sensing field. The Mercator aircraft will transit other airspace classes.

It should be noted that strictly speaking, neither flight rule (IFR - Instrument Flight Rules or VFR - Visual Flight Rules) is applicable to UAV flight, since both require a pilot on board of the aircraft.

\subsection{Responsibilities}

Many authorities are involved when trying to fly an unmanned aircraft. On the regulatory side, the Belgian Civil Aviation Authority (Federale Overheidsdienst Mobiliteit en Vervoer,
Directoraat-Generaal Luchtvaart) is responsible for granting the Permit-to-Fly for all unmanned aircraft lighter that $150 \mathrm{~kg}$ (heavier UAVs are regulated by EASA, the European Aviation Safety Agency). This is ruled by the Belgian Certification Specification for UAV Systems [ref], and it focuses on the technical aspects of aircraft safety.

Another part of the evaluation is air traffic safety, which is evaluated by the Air Navigation Service Providers (ANSP) that are active in Belgium. There are three of them:

- $\quad$ Belgocontrol, for civil aiviation below $24500 \mathrm{ft}$;

- $\quad$ ATCC, for aviation in military airspace;

- $\quad$ Eurocontrol, for civil aviation above $24500 \mathrm{ft}$.

Their role is to assess the impact of a UAV flight on air traffic safety and report on that to Belgian CAA.

Thirdly, as a UAV needs to be remotely controlled, the Belgian authority for radio communication needs to be consulted, and transmission licences have to be granted.

Finally, Belgian Defence is responsible to grant permission to use the Bertrix airfield and its infrastructure. 


\section{THE APPROACH USED FOR MERCATOR}

\subsection{The Mercator aircraft}

Mercator (Figure 1) is a solar powered aircraft designed to fly at lower stratospheric altitude $(15-20 \mathrm{~km})$ for very long duration, carrying a $2.6 \mathrm{~kg}$ high resolution camera, called MEDUSA. It has a wingspan of approximately $22 \mathrm{~m}$, and a total mass of about $50 \mathrm{~kg}$. Its wings are covered with a thin film solar array, which produces the electrical energy for propulsion, avionics and the payload. During day time, excess energy is used to charge a string of batteries that provide power during night time. Although these are the best to be found in the world, they cannot keep the aircraft at the highest altitude all night. So, during night time, the aircraft slowly descends as well.

\subsection{Early attempt}

The Mercator project started in June 2006, before Belgian CAA had issued its Certification Specification. In absence of clear rules, an safety case approach was proposed. The basis of that is to show that the proposed UAV flight has an equivalent level of safety (ELOS) as other air traffic, and hence it should be allowed to fly. This safety case was a mathematical model, and it proved that the Mercator aircraft poses significantly less threat to other aircraft or people on the ground than commercial aircraft.

However, important issues remained. The UAV was not equipped with a transponder, and it did not carry navigation lights. Since the airframe is predominantly made of composites, it reflects almost no RADAR waves, so the only way for Air Traffic Control to "see" the aircraft is via secondary RADAR (a transponder). At night, other aircraft pilots would be unable to see Mercator, with unacceptable collision risks as a consequence, since Mercator does not have a "sense-and-avoid" system, nor the reaction capability to avoid other air traffic.

A workaround for the lack of a transponder was proposed: injecting Mercator's position (received via telemetry from the on-board GPS receiver), but this involved unacceptable changes to the infrastructure of the ANSPs. Furthermore, GPS altitude is not accepted in aviation, which is based on pressure altitude. So, an alternative approach had to be found.

\subsection{A new aircraft}

The early attempt had significant consequences: the Certification Specification for UAVs was issued, leading to more clarity in what the authorities needed. A transponder and navigation lights were clearly required.

The impact on the Mercator aircraft is considerable: adding a transponder and lights adds about $1 \mathrm{~kg}$ to the aircraft's mass, and both draw power. This is a concern during night time, when batteries power the aircraft. In fact, the aircraft design had to be modified to be able to carry the extra equipment and still meet the criteria set by Pegasus.

This new design proved its air worthiness in a flight trial in the USA, in July 2010, when the aircraft, called Zephyr, flew for more than 14 days, breaking several world records.

\subsection{Building confidence}

Rather than coming up with a set of documents in the hope that they would be acceptable, we took the initiative to set up a meeting with all relevant parties to kick off the new attempt. This meeting was attended by representatives from Belgian CAA (who were kind enough to host te meeting), Belgocontrol,
ATCC, Eurocontrol as well as from QinetiQ (aircraft designer and builder) and VITO.

The outcome of this meeting was that a positive attitude was shown by all, and also that this project was going to serve as a test for the procedures, because they had never been applied to this case before.

It was agreed that all would work together; the project was placed at a high level of priority.

\subsection{A launch location}

The Mercator aircraft is hand launched (3-5 persons carry it above their heads and run for no more than 20 meters before the aircraft lifts off), so there is no formal need for a runway or an airfield to start from. However, there are a number of rarely used airfields in Belgium that offer facilities (a hangar, communication lines, ...) and are marked on aeronautical charts. So it was decided to try to use an existing airfield, to minimise impact on the working methods of air traffic controllers.

The aircraft climbs slowly at low altitude, so sufficient distance from obstacles was required, which reduced the possibilities. In the end, two alternatives (both military, with very little traffic) were selected and proposed to the other parties. One was considered to be too close to Brussels airport, so the remaining option was then the baseline for operations: NATO reserve airfield Bertrix (designated EBBX).

Operating on a military installation, even when it is only used infrequently, needs to be approved by the Minister of Defense. We applied for an authorisation, and obtained it. From that point onwards, support from all sections in Belgian Defense was strong. One important asset was that we could use the services of the Meteo Wing, who are trained in weather predictions for aviation.

\subsection{A stepwise approach}

Now, we proposed to execute three flights, to test and validate the procedures, and to show that the Mercator flights were indeed safe.

Flight 1 was to take off at dawn and land at dusk (so fly for about 12 hours), carrying transponder and navigation lights, but no payload, flying to no more than $24500 \mathrm{ft}$, so that it did not interfere with Eurocontrol MUAC operations.

Flight 2 would extend the duration to 24 hours (take-off and landing at dawn), with transponder and navigation lights, and climbing to more than $24500 \mathrm{ft}$, hence involving Eurocontrol as well.

Flight 3 would fly for 3 consecutive days, and carry the MEDUSA camera as well as transponder and navigation lights. Target altitude was over $60000 \mathrm{ft}$ during day time and more than $35000 \mathrm{ft}$ at night.

In a following meeting, Flight 1 was considered to be unnecessary by ANSPs and Belgian CAA, so it was dropped. In parallel to supplying Belgian CAA with the technical documents of the aircraft and crew, the ANSPs worked on the operational scenario of the flights. Closing a substantial part of the air space to all other traffic did not seem to be a viable option to them. This was an advantage to the Pegasus project, because it aims at providing remote sensing capability above Europe and other inhabited regions.

All flights use class C airspace, so separation between Mercator and other air traffic is done by ATC. For that reason, Belgian CAA requires that at least one member of the Ground Control Station crew has an Instrument Rating. This ensures that conversation to and from ATC is done in the manner used by all pilots. 
The result of the ANSPs collaboration was an operational method to create a dynamic buffer around the aircraft in 3 dimensions, into which other air traffic was not allowed. Only during ascent and decent, a part of the airspace was to be closed to all other air traffic (TRA/TSA UAV Bertrix on Figure 2.). Of course, only part of the Belgian airspace was available for this exercise (the Belgian part of TRA S2 Beauraing and TRA S5

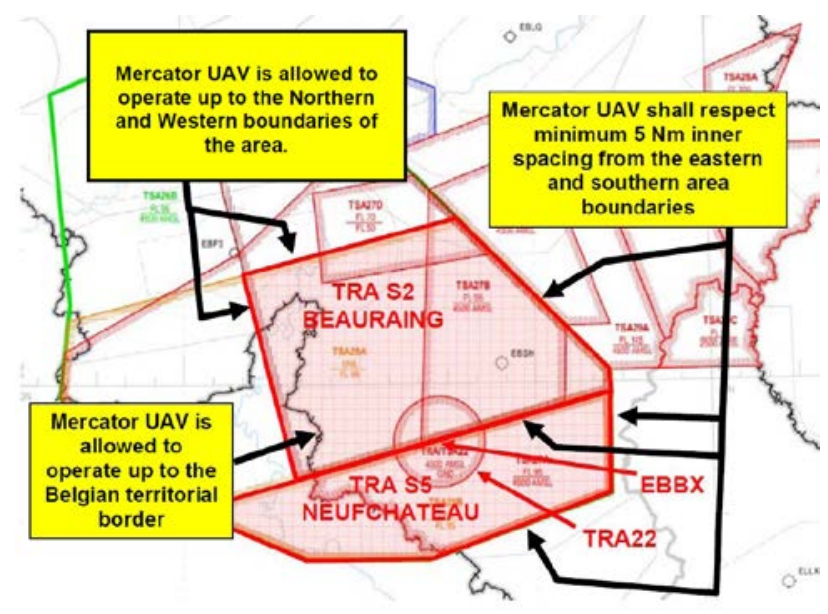

Figure 2. Airspace available for Mercator

Neufchateau in Figure 2.), measuring about 55 km East-to-West and North-to-South The flight crew would have to deal with this restriction and keep the aircraft within its containment area.

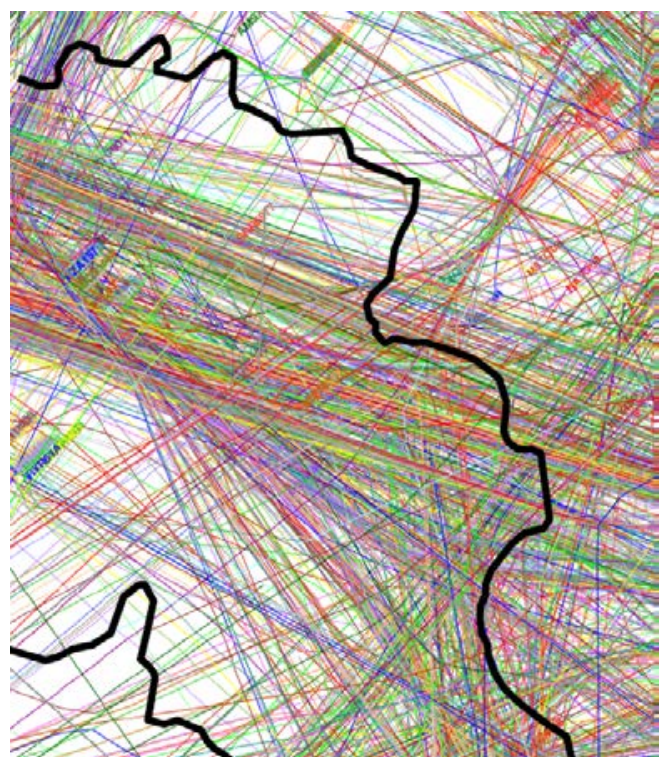

Figure 3. Real flown trajectories above $24500 \mathrm{ft}$, on March 24, 2010, above the flight area for Mercator

\subsection{Communication}

For air traffic control, it is mandatory that clear communication with the pilot is guaranteed. For Mercator, this created another challenge. Ideally, the aircraft should carry a repeater to relay the pilot's voice communication to the traffic controller and vice versa. This would again increase mass, power consumption, so alternatives were explored.

Receiving ATC broadcast and transmitting to them from the location of the ground control station was not possible. The Bertrix airfield sits in the shadow of surrounding hills.
Relaying the communication to a receiver/transmitter in the vicinity of the ATC installations was considered, but rejected as too costly and risky.

Finally, the ANSPs accepted to use dedicated telephone lines during the flights. Thanks to Belgian Defence, both the public and the defence networks could be used, creating redundancy to Belgocontrol and ATCC. Eurocontrol MUAC is situated in Maastricht, The Netherlands, so it could not be connected to the Belgian Defence network. On top of that mobile phones using different networks were also used.

Radio broadcast licences were also applied for, to command and control the aircraft and receive its telemetry, and to downlink the payload data.

\section{FLIGHT EXECUTION}

\subsection{Autumn of 2010}

By the end of August 2010, all permissions were granted. The aircraft and flight team (QinetiQ) then prepared for the flight, and transport was arranged. The aircraft and GCS arrived in Bertrix in the first week of October. The preparation team assembled the aircraft, set up the GCS and took everything through a series of pre-flight tests.

A representative of Belgian CAA travelled to Bertrix to check the final paperwork and to verify that the aircraft transponder was in good working order.

By the morning of October $12^{\text {th }}$, all were ready to fly, provided suitable weather conditions were present. Unfortunately, the early Autumn "Indian Summer" conditions that prevailed over the preceding weekend were replaced by stronger winds and rain. This did not change substantially over the three following weeks. So, by the end of October, the aircraft was disassembled and returned to the UK.

\subsection{Debrief and moving forward once again}

Even though the flight did not take place, several small issues with the procedures were identified.

For instance, at some point in time, a military helicopter exercise had to be allowed on the airfield. This was not accounted for in the operations manual, so a workaround had to be found to co-use the field and airspace.

All of these items were carefully examined and addressed in a new operational procedure.

A new application for Flight 2 (Flight 1 had been cancelled) was made, and again all permits and radio licences were obtained to execute Flight 2 once again, in the May-June 2011 flight window. Examining the weather, this period looked more suitable for a flight than the previous one.

\subsection{May-June 2011}

As for the previous attempt, everything was put in place to be ready to fly from May $1^{\text {st }}$ onwards. And, once again, these preparations were done under favourable weather conditions, so that everyone was optimistic and in high spirits.

Meteowing forecasters were now very well informed about the weather requirements for a flight. They were related to the aircraft as well as to the containment area.

The aircraft needs to be able to overcome the wind, so that it can stay in the containment area; with true air speed at ground level of about 12 knots going up to 40 knots at $60000 \mathrm{ft}$, this is a challenge. Also, moisture and icing risks are absolute showstoppers. Finally, at low level, turbulence can make the 
aircraft crash in an instant, which is why a dawn launch is preferred. Just before or after dawn, there is a brief period when winds die down.

On several occasions, a potential flight opportunity appeared in the 5-day forecasts of Meteo Wing, but it then lost its appeal in following forecasts. The flight team returned to the UK, ready to deploy at the first possibility.

Close to the end of the flight window, it appeared that a flight might be possible just after the close of the window. In just a few days, requests to extend the permits and licences were sent out and answered positively, thanks to the support of many people in different administrations.

Still, the opportunity did not consolidate to a weather situation in which the flight crew considered it to be safe to fly, and once again, Flight 2 did not take place in this flight period either. It is currently postponed to 2012 .

\subsection{Flight 3}

Flight 3 is what we want to achieve: it carries the MEDUSA camera, and it has a 3 days endurance at least, allowing us to demonstrate the unique remote sensing solution that Pegasus is. At present, we have obtained a Permit-to-Fly for this, but one of its conditions is a successful Flight 2. This is completely in line with our proposed step-wise approach, and we hope to also execute Flight 3 in 2012.

\section{CONCLUSIONS}

Although we have yet to fly Mercator in Belgium, a massive amount of work has been done, and many hurdles were passed. We have had the opportunity to work closely with aviation authorities and air navigation service providers. Even though they are responsible for a very busy airspace, all were enthusiastic and prepared to find new operating methods to accommodate the Mercator flights, as they see that UAV flights will become more frequent in the coming years.

Safety is the key issue when dealing with aviation, and UAV flights should address this in a just as serious way as other airspace users. Using UAV platforms for remote sensing and photogrammetry requires a commitment from our community to behave responsibly.

\section{REFERENCES}

Biesemans J., Sterckx S., Knaeps E., Vreys K., Adriaensen S., Hooyberghs J., Deronde B., 2007. Image processing workflows for airborne remote sensing. In Proceedings of the 5th EARSeL SIG Imaging Spectroscopy Workshop,Bruges, Belgium.

CAP 493, 2011. Manual of Air Traffic Services Part 1. UK Civil Aviation Authority, Norwich, UK.

Delauré, B., Van Achteren, T., Everaerts, J., Livens, S., Beghuin, D., 2008. Assembly and test of MEDUSA, a multispectral instrument for stratospheric Earth observation, Proc. SPIE 7106, 710619 (2008.).

Eurocontrol, 2010. EUROCONTROL Long-Term Forecast: IFR Flight Movements 2010-2030. Eurocontrol Headquarters, Brussels, Belgium.

Everaerts, J., Lewyckyj, N., Fransear, D., 2004. PEGASUS: Design of a Stratospheric Long endurance UAV System for
Remote Sensing. International Archives of the Photogrammetry, Remote Sensing and Spatial Information Sciences, Vol. XXXV, Part B1. 